\title{
DR-1832
}

[1-8]

\section{Identification of Genetic Variants in Y-Chromosome Specific Genes Associated with Seminal Production in Murrah Buffaloes}

\author{
P. Ramajayan, S.N. Sivaselvam, S.M.K. Karthickeyan, A. Gopinathan
}

10.18805/ajdfr.DR-1832

\begin{abstract}
Background: Marker assisted selection based strategies are essential to identify superior quality bulls at an early age for frozen semen production. The present study aims to determine the genetic variants in the Y-chromosome specific genes, sex determining region on Y-chromosome ( $S R Y)$ and testis specific protein Y-encoded (TSPY) in association with semen production traits in Murrah buffalo bulls.

Methods: The genomic DNA extracted from the blood samples of 70 Murrah buffalo bulls maintained under semen production in the frozen semen station were utilized for PCR amplification. The sequences of SRY and TSPY genes were screened for single nucleotide polymorphism using the seqman module of DNASTAR LASERGENE software. The single nucleotide variations in comparison with reference sequences and phylogenetic tree construct were obtained using Clustal $W$ and MegAlign module.

Result: The analysis revealed that the sequences of SRY and TSPY genes were monomorphic in nature, devoid of variations specifying that the sequences are highly conserved among the Murrah buffalo bulls studied. Hence, association studies with seminal traits could not be performed. However, the exon sequence of $S R Y$ gene of Murrah buffalo showed a single nucleotide variation at position $209(\mathrm{G}<\mathrm{A})$ compared to the sequences of Nili-Ravi and Kundi buffaloes. Similarly, the TSPY gene exhibited a significant number of single nucleotide variations compared with Bos taurus sequences. The phylogenetic tree analysis evinced a close genetic relationship with less divergence between Murrah buffalo and other buffalo breeds and species in the bovinae family. Further extensive studies on SRY, TSPY and other Y-chromosome specific genes in a large, diverse population of Murrah buffalo bulls could help to discover a considerable number of SNP markers related to semen production for the early selection of breeding bulls.
\end{abstract}

Key words: Monomorphic, Murrah buffalo bull, SRY, TSPY, Y-Chromosome.

\section{INTRODUCTION}

Buffalo (Bubalus bubalis) contributes significantly to milk, meat and draught power as important livestock genetic resource of India. Around $49 \%$ of total milk production and $19.05 \%$ of total meat production in India is contributed by indigenous and non-descriptive buffaloes (Anonymous, 2019). Murrah buffalo is the most commonly used breed for genetic up-gradation of non-descript buffaloes to enhance the genetic quality and augment production performance. To improve the genetic merit of non-descriptive and indigenous buffaloes, the present-day breeding program utilizes the frozen semen doses of genetically superior bulls to cover a larger population. The bulls used for frozen semen production are selected at an early age based on the production performance of the dams and sires, body weight and scrotal development. However, poor semen quality, poor libido, low post-thaw motility and sperm abnormalities are the constraints observed even in superior bulls selected for semen production, which is governed by genetic and environmental factors (Kaur et al., 2014). Therefore, it is important to develop molecular marker techniques to accurately estimate the fertility levels of breeding bulls at a younger age. The fertility of bull is mainly governed by the group of genes in the $\mathrm{Y}$ - chromosome, which plays a major role in spermatogenesis, spermatocytes structural and functional stability, sex differentiation and sexual development (Mukherjee et al., 2013). Thus, the genes
Department of Animal Genetics and Breeding, Madras Veterinary College, Tamil Nadu Veterinary and Animal Sciences University, Chennai-600 051, Tamil Nadu, India.

Corresponding Author: P. Ramajayan, Department of Animal Genetics and Breeding, Madras Veterinary College, Tamil Nadu Veterinary and Animal Sciences University, Chennai-600 051, Tamil Nadu, India. Email: dr.ramvet1990@gmail.com

How to cite this article: Ramajayan, P., Sivaselvam, S.N., Karthickeyan, S.M.K. and Gopinathan, A. (2022). Identification of Genetic Variants in Y-Chromosome Specific Genes Associated with Seminal Production in Murrah Buffaloes. Asian Journal of Dairy and Food Research. DOI: 10.18805/ajdfr.DR-1832.

Submitted: 27-10-2021 Accepted: 05-01-2022 Online: 14-02-2022

regulating semen production could be viewed as major candidate genes in determining the semen production capability and fertility of bulls. Therefore, identification of single nucleotide polymorphisms (SNPs) in the genes associated with seminal attributes would help to find suitable SNP markers for the screening of bulls with better semen production. The marker-assisted selection will aid to select the bulls at an early stage, which will facilitate early adoption to the training, environmental condition and managemental practices to produce quality frozen semen with minimal rejection. Hence, in the present investigation, Y-chromosome specific genes such as sex determining region on $Y$ - 
chromosome (SRY) and Testis Specific Protein Y-encoded ( $T S P Y)$ were characterized to identify the genetic variations in association with semen production in Murrah buffalo bulls.

\section{MATERIALS AND METHODS}

The blood samples and seminal data were collected from 70 Murrah buffalo bulls maintained in the frozen semen station of Exotic Cattle Breeding Farm, Thanjavur, Tamil Nadu, India. A total of 10578 ejaculates data on seminal traits such as semen volume, sperm concentration, total sperm per ejaculate, mass activity, initial motility, post-thaw motility and frozen semen doses per ejaculate were utilized for the study. The experiment was conducted in 2016 at the Department of Animal Genetics and Breeding, Madras Veterinary College, Chennai.

\section{DNA extraction}

Around $10 \mathrm{ml}$ of blood samples from the jugular vein were collected in sterile Becton-Dickinson vacutainers coated with $0.12 \mathrm{ml}$ of $0.5 \%$ EDTA solution. The genomic DNA was isolated by Phenol-Chloroform method with slight modification using DNAzol reagent instead of SDS and proteinase K (Sambrook et al., 1989). The quality of DNA was checked in $0.8 \%$ agarose horizontal gel electrophoresis using 0.5X TAE as running buffer. The purity and concentration were estimated using Nanodrop Biospectrophotometer. The DNA working concentration of 20$50 \mathrm{ng} / \mu \mathrm{l}$ was prepared from DNA samples with nucleasefree water and stored at $-20^{\circ} \mathrm{C}$ till further process.

\section{Primer designing}

Using "Primer3" online software (http://frodo.wi.mit.edu/ primer3/), the primers for the exons of SRY and TSPY genes were designed taking Bos taurus sequences of $S R Y$ (Gene ID with accession number: 280931-NM001014385.1 ) and TSPY (Gene ID with accession number: 281554-NM-001244608.1) genes as reference. The exons were selected with adjoining intronic regions to amplify the complete exons precisely. The primers were analyzed in Oligo Analyzer 1.0.3 software for GC content, selfannealing and primer loops to achieve the best primer pairs. The primers were synthesized at M/s. Eurofins Genomics India Pvt. Ltd., Bangalore and supplied in lyophilized form with OD values of 4.2-14.8 to arrive at the final concentration of $100 \mathrm{pmol} / \mu \mathrm{l}$ from which working concentration of 10 picomoles was prepared. The primer sequences, product sizes and annealing temperatures are furnished in Table 1.

\section{PCR amplification}

The polymerase chain reaction (PCR) was carried out in $15 \mu \mathrm{l}$ reaction volume with PCR master mix, primers and genomic DNA using thermal cycler. Based on the quality of PCR product from gradient PCR, the annealing temperature of primers was standardized. About $4 \mu \mathrm{l}$ of PCR products were run in $2 \%$ agarose gel containing $0.5 \mu \mathrm{g} / \mathrm{ml}$ ethidium bromide along with $50 \mathrm{bp}$ DNA ladder at a voltage of $100 \mathrm{~V}$ for 45 minutes. The product size was verified using UV transilluminator and documented with gel documentation system. The details on PCR reaction mixture and PCR conditions are presented in Tables 2 and 3 .

\section{Sequencing and analysis}

The PCR products were sequenced using ABI PRISM 3730 XL Genetic Analyzer from both ends by M/s. SciGenom Labs Pvt. Ltd., Cochin. The single nucleotide polymorphism within the sequences of Murrah buffalo bulls was analyzed using the Seqman module of Dnastar Lasergene software, taking Bos taurus DDX3Y gene sequences as reference. The single nucleotide variations in the sequences of Murrah buffalo in comparison with reference sequences were determined using Clustal W sequence alignment (MegAlign module). The phylogenetic tree and genetic distance were obtained using the Neighbour-Joining (NJ) with 1000 bootstrap method of MegAlign module. The mean value for the semen production traits were estimated as per the statistical procedure of Snedecor and Cocharan (1989).

Table 1: Primer sequences and their annealing temperature of Y-specific genes.

\begin{tabular}{|c|c|c|c|}
\hline Exons & Primer sequence $\left(5^{\prime} \rightarrow 3^{\prime}\right)$ & $\mathrm{T}_{\mathrm{a}}\left({ }^{\circ} \mathrm{C}\right)$ & Productsize $(\mathrm{bp})$ \\
\hline \multicolumn{4}{|c|}{ Sex determining region on Y-Chromosome (SRY) } \\
\hline \multirow[t]{2}{*}{ SRY } & F: CGC AGT GCA GTC GTA TGC TTC TGC & 61 & 736 \\
\hline & R: AGC GCC TTT GTT AGC GAG AGT AAG & & \\
\hline \multicolumn{4}{|c|}{ Testis specific protein Y-encoded (TSPY) } \\
\hline & F: CTA GTC GGT CCC ACA GGT TT & 54 & 756 \\
\hline \multirow[t]{2}{*}{ TSPY I } & R: AGT TAA GGC TCC TGG TGT CC & & \\
\hline & F: ATC CTT GTT CCA CCC CAG AC & 57.5 & 645 \\
\hline \multirow[t]{2}{*}{ TSPY II } & R: AGT TAA GGC TCC TGG TGT CC & & \\
\hline & F: GAT GAG TGT GGG TGT GCA AG & 59.3 & 686 \\
\hline \multirow[t]{2}{*}{ TSPY III } & R: ATT CAC CCT GCC TCT AGT CG & & \\
\hline & F: AGG ACA TGG TGC CTA GTG AC & 57 & 606 \\
\hline TSPY IV & R: TTC GGG TCT CTG CTC TTC TC & & \\
\hline
\end{tabular}

F-Forward; R-Reverse; $\mathrm{T}_{\mathrm{a}}$ - Annealing temperature. 


\section{RESULTS AND DISCUSSION}

The $S R Y$ gene is an intronless gene with a single exon of $690 \mathrm{bp}$ representing the entire gene. The TSPY gene consists of 7 exons with sequence lengths of $124 \mathrm{bp}, 416$ bp, $78 \mathrm{bp}, 111 \mathrm{bp}, 145 \mathrm{bp}, 108 \mathrm{bp}$ and $213 \mathrm{bp}$, respectively. Four pairs of primers for TSPY gene and single primer for $S R Y$ gene were designed to amplify the whole exons by enclosing the intronic regions adjacent to the exons (Fig 1). The sequence length of $736 \mathrm{bp}$ covering the single exon was amplified, which comprised the total length of $S R Y$ gene. In TSPY from the entire gene length of $3206 \mathrm{bp}$, the nucleotide sequence of 2693 bp covering seven exons was amplified, which comprised $84 \%$ of the gene. With respect to seminal traits, the overall mean value for semen volume, sperm concentration, total sperm per ejaculate, mass activity, initial motility, post-thaw motility and frozen semen doses per ejaculate was $2.56 \mathrm{ml}, 1338.58$ million per $\mathrm{ml}$, 3189.23 million, $3.59,76.58 \%, 53.67 \%$ and 138.84 doses, respectively (Table 4 ).

The analysis of sequences revealed that the exons and its bordering intron sequences of SRY and TSPY genes were monomorphic and no variation was noticed in the studied population of Murrah buffalo bulls (Fig 2). To confirm the monomorphism, duplicate samples were sequenced and analysed, which also displayed a lack of variations in the sequences. These findings suggest that the sequences of $S R Y$ and TSPY genes are highly conserved among the

Table 2: Composition of PCR reaction mixture.

\begin{tabular}{lc}
\hline Components & Volume $(\mu \mathrm{l})$ \\
\hline Master Mix (Ampliqon) & 7.5 \\
Primer-Forward and reverse (10 pmoles) & $0.5-0.8$ \\
Template DNA & 1.5 \\
Millipore water & $5.5-5.2$ \\
Total & 15 \\
\hline
\end{tabular}

Table 3: PCR Reaction condition.

\begin{tabular}{lcr}
\hline Process & Temperature & Duration \\
\hline Initial denaturation & $95^{\circ} \mathrm{C}$ & 5 minutes \\
Cyclic denaturation & $95^{\circ} \mathrm{C}$ & 35 seconds \\
Primer annealing & Varied with the primer & $35-45$ seconds \\
Primer extension & $72^{\circ} \mathrm{C}$ & $45-60$ seconds \\
Back to steps 2 to 4 & \multicolumn{2}{c}{$\mathbf{3 5}$ cycles } \\
Final extension & $72^{\circ} \mathrm{C}$ & 10 minutes \\
Hold & $4^{\circ} \mathrm{C}$ & Forever \\
\hline
\end{tabular}

Table 4: Mean values of semen production traits.

\begin{tabular}{lcr}
\hline Traits & No. of ejaculates & Mean \pm S.E. \\
\hline Semen volume (ml) & 10578 & $2.56 \pm 0.01$ \\
Sperm concentration (million/ml) & 10578 & $1338.58 \pm 2.23$ \\
Total sperm/ejaculate (million) & 10578 & $3189.23 \pm 8.75$ \\
Mass activity (0 to 5 scale) & 10578 & $3.59 \pm 0.01$ \\
Initial motility (\%) & 10578 & $76.58 \pm 0.07$ \\
Post-thaw motility (\%) & 10578 & $53.67 \pm 0.03$ \\
Frozen semen doses/ejaculate & 10578 & $138.84 \pm 0.41$ \\
\hline
\end{tabular}

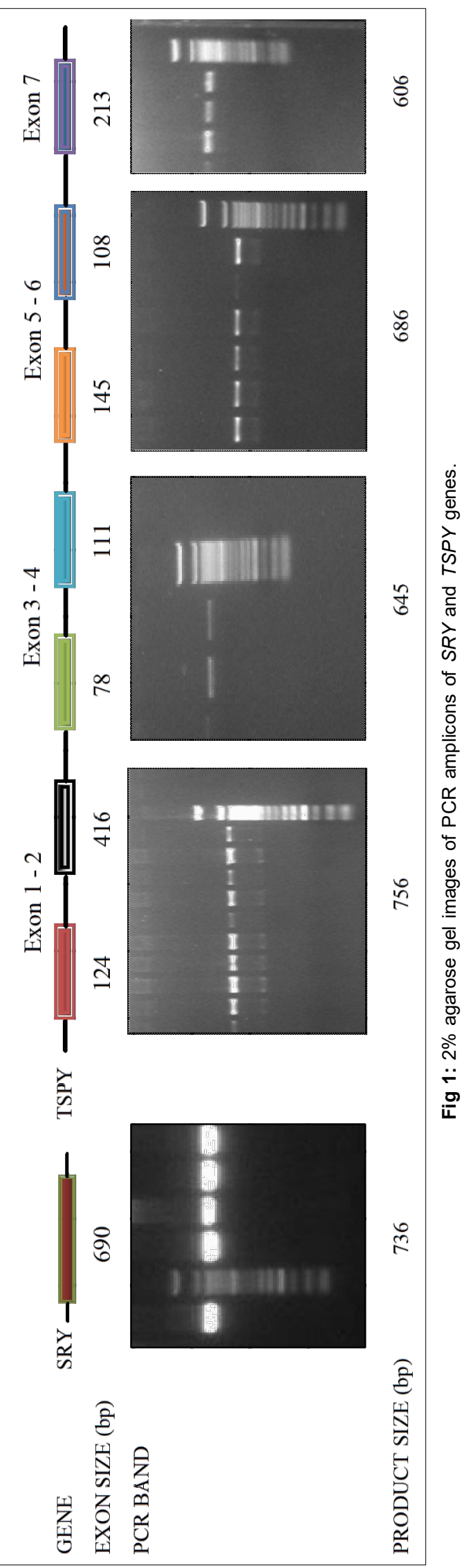




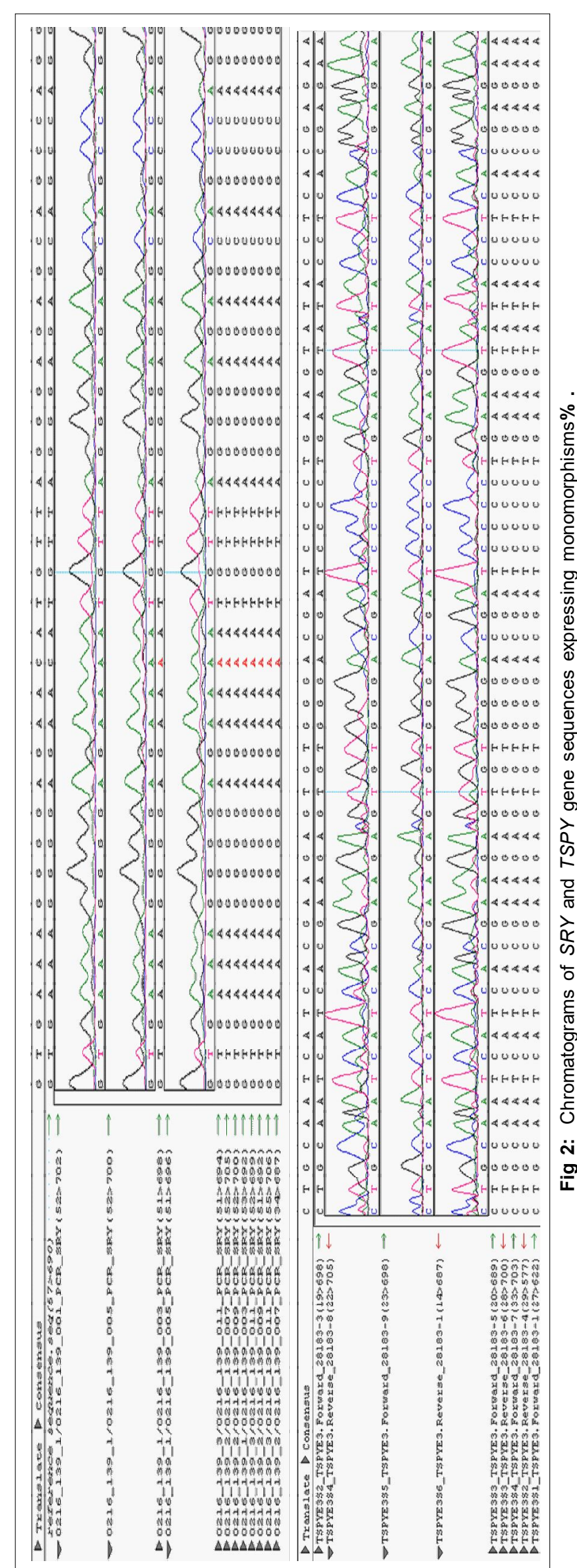

studied Murrah buffalo bulls and hence association studies with semen production traits could not be performed. The multiple sequence alignment of $S R Y$ gene sequence of Murrah buffalo showed $99 \%$ homology with the sequences of Nili-Ravi (accession no.: JX668002.1) and Kundi buffaloes (accession no.: JX667995.1) and 96\% homology with Bos taurus (accession no.: NM-001014385.1) and Bos indicus (accession no.: U15569.1). The exon sequence of SRYgene of Murrah buffalo possessed a nucleotide variation at position $209(\mathrm{G}<\mathrm{A})$ when compared with the sequences of Nili-Ravi and Kundi buffaloes. Similarly, at position 592 $(G<A)$, variation was observed between Murrah and NiliRavi buffaloes (Fig 3). With respect to TSPY gene in comparison with Bos taurus sequences, at position 1901, $1915(\mathrm{G}<\mathrm{T}), 1924(\mathrm{G}<\mathrm{A}), 1935(\mathrm{G}<\mathrm{C}), 1960(\mathrm{G}<\mathrm{A})$, 1975(G<T), $1990(G<C), 2007-8,(A<T), 2027(C<G), 2101-$ $2(\mathrm{~T}<\mathrm{C}), 2125(\mathrm{G}<\mathrm{C}), 2178(\mathrm{G}<\mathrm{A}), 2217(\mathrm{G}<\mathrm{C}), 2231(\mathrm{~T}<\mathrm{A})$, $2234(\mathrm{~A}<\mathrm{C}), 2238(\mathrm{G}<\mathrm{A}), 2242(\mathrm{C}<\mathrm{T}), 2267(\mathrm{~T}<\mathrm{G}), 2286$ $(C<T), 2301(A<T), 2318(A<T), 2330(C<T), 2334(G<A)$, $2338(G<A), 2359(A<G), 2382(A<C), 2398(G<A), 2411$ $(\mathrm{G}<\mathrm{T}), 2417(\mathrm{G}<A), 2433(\mathrm{G}<\mathrm{T}), 2444(\mathrm{G}<\mathrm{C}), 2456(\mathrm{G}<\mathrm{C})$, $2463(C<G), 2466(G<T), 2469(A<G), 2488(G<A)$ and 2493 $(C<A)$ nucleotide variations were noticed in exon 3 and its intronic regions (Fig 4). The sequence of exon 4 and alongside intronic part expressed variations at position 2905, $2922(\mathrm{C}<\mathrm{T}), 2933(\mathrm{G}<\mathrm{A}), 2937(\mathrm{~A}<\mathrm{T}), 2956(\mathrm{C}<\mathrm{G}), 2957$ $(T<G), 2971(G<A), 2973,2975(T<G), 2998(G<A), 3017$ $(A<C), 3019(G<A), 3038,3069(G<T), 3074(C<G), 3077$ $(A<T), 3085(C<T), 3086(A<G), 3088(C<T), 3091(C<A)$, $3100(A<C), 3106(G<C), 3112(G<A), 3124(A<T), 3130$, $3138(A<G), 3145(C<A), 3162(G<C), 3170(C<A), 3176$ $(\mathrm{T}<\mathrm{C})$ and $3198(\mathrm{C}<\mathrm{T})$, respectively (Fig 5$)$.

To determine the homology level, the phylogenetic tree was established by comparing the SRY and TSPY gene sequences of Murrah buffalo and other closely related species in the Bovidae family. The phylogenetic tree analysis of $S R Y$ gene sequences revealed three separate clades, consisting of all buffalo breeds in one group, cattle species in the second clade and caprinae species in another group (Fig 6). The close genetic relationship between buffalo breeds, Bos taurus, Bison bison and Bos indicus indicates that these regions are more conserved among bovinae species, though they differ structurally. Similarly, the phylogenetic tree construct of TSPY gene expressed less divergence and close genetic association of Murrah buffalo with other buffalo breeds followed by Bos taurus and Bos grunniens, respectively (Fig 7). The phylogenetic analysis of present study is in accordant with Hussain et al. (2013), who studied the phylogenetic relationship between Nili Ravi and Kundi buffaloes with other bovine species.

The mean semen volume obtained in the present study is consistent with the results of Kumar and Krupakaran (2014) and Bhakat et al. (2015); however, higher values (Kaustubh et al., 2020 and Singh et al., 2013) were also recorded. The findings on mean sperm concentration, total sperm per ejaculate, mass activity and post-thaw motility 


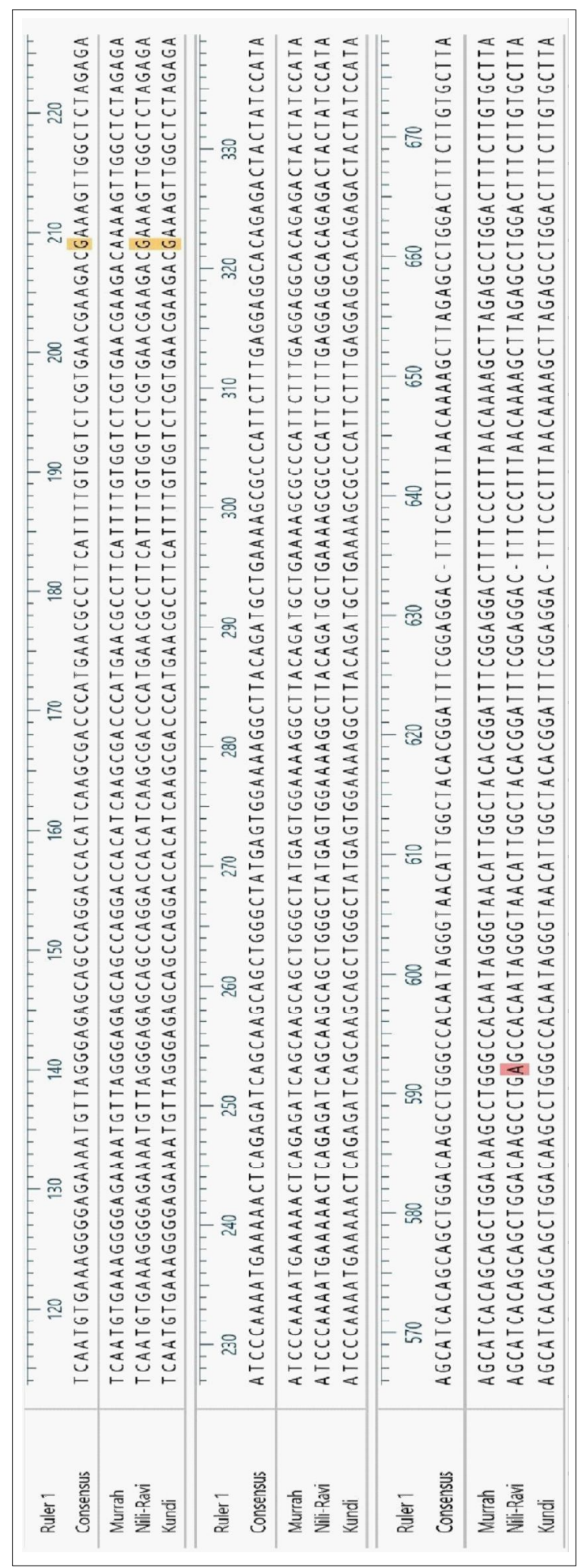

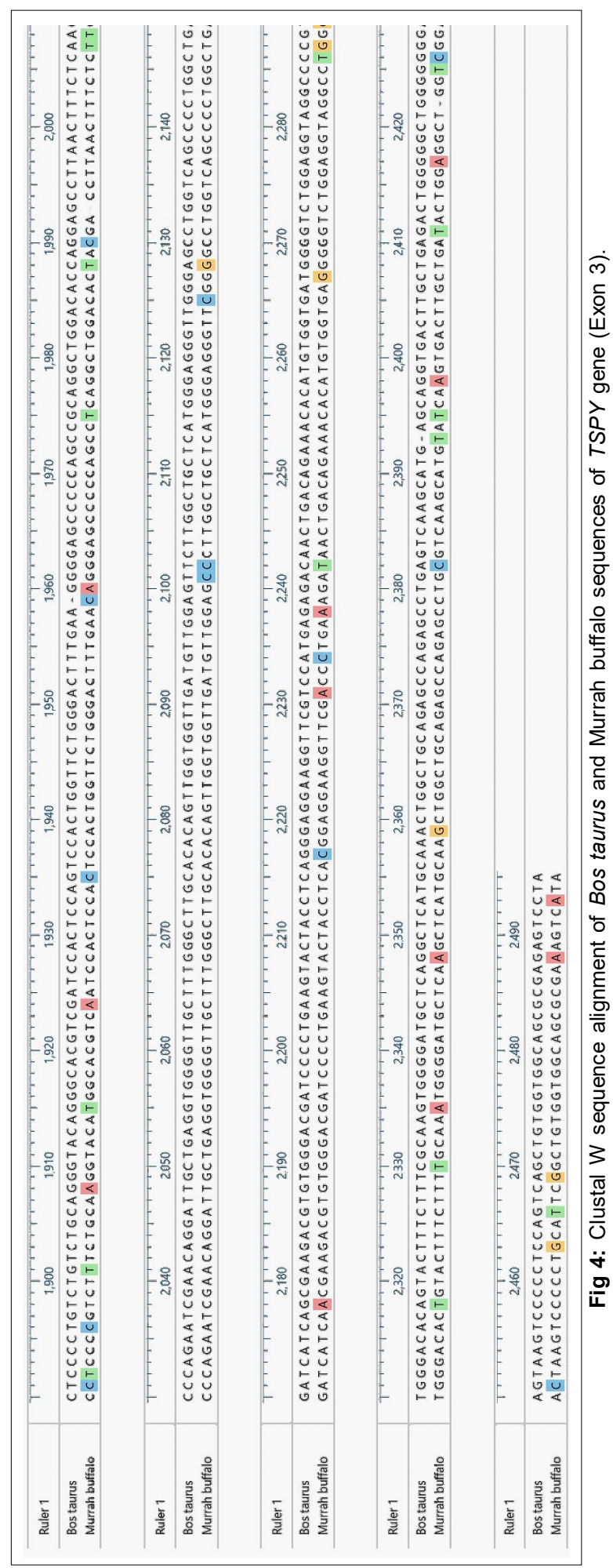



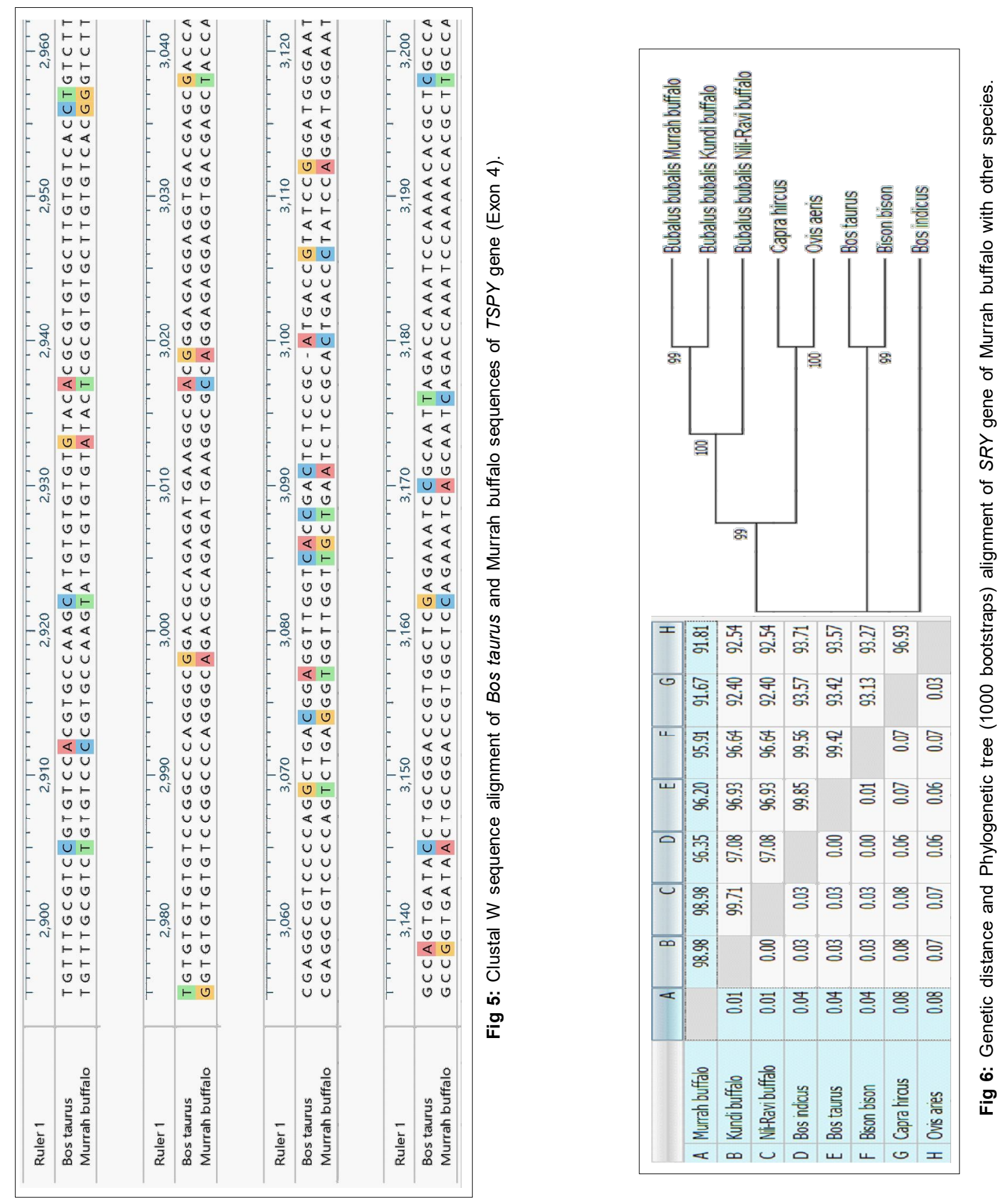


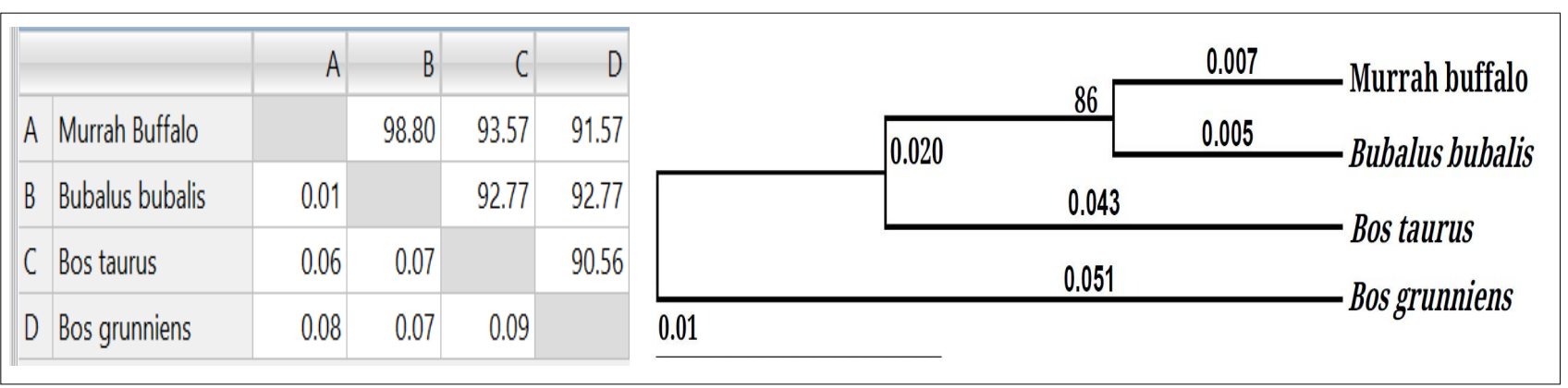

Fig 7: Genetic distance and Phylogenetic tree (1000 bootstraps) alignment of TSPY gene of Murrah buffalo with other species.

reported in this study were comparatively higher than that of earlier records (Kaustubh et al., 2020; Bhakat et al., 2015; Kumar and Krupakaran, 2014 and Singh et al., 2013), except the increased total sperm per ejaculate ( 4560 million) by Kaustubh et al. (2020). Compared with the present outcome on initial motility, a higher value of $79.5 \%$ by Singh et al. (2013) and a lower value of $60.64 \%$ by Bhakat et al. (2015) were noted. The average frozen semen doses per ejaculate of 138.84 is in close accordance with the report of Ravimurugan (2001). These results state that the bulls selected might be of superior germplasm with quality semen production ability.

Earlier studies had shown that Y-specific genes play a major role in semen production, but studies on polymorphic markers as a tool of selection of breeding bulls are very minimal in buffaloes. The absence of variation in the studied genes attributes to the bulls maintained in the semen station, which are all good in quality semen production selected based on genetic merit from the home tract. The highly conserved and monomorphic nature of SRY and TSPY genes observed in the present study are consistent with the findings of Mukhopadhyay et al. (2011). However, Jayakumar (2006) found nine polymorphic variations in the $S R Y$ gene of Murrah buffaloes compared to Chinese swamp buffaloes. Similarly, SNP was also identified in Nili-Ravi and Kundi buffaloes compared with swamp buffaloes (Hussain et al., 2013). The greatest homology existing between the exons of TSPY gene in the screened Murrah bulls is in agreement with the findings of Gopinathan (2014), who reported precise conservation of the sequence of TSPY gene in crossbred cattle. However, Mukhopadhyay et al. (2011) found an SNP at the fourth intron of the TSPY gene in Murrah buffalo bulls but did not possess any significant association with semen production traits.

\section{CONCLUSION}

The genetic characterisation of SRY and TSPY genes in the detection of polymorphic markers unveiled that the sequences are highly conserved with no variation among the studied population of Murrah buffalo bulls. Howbeit, single nucleotide variations were noticed at position $209(\mathrm{G}<\mathrm{A})$ in Murrah buffalo bulls when compared with Nili-Ravi and Kundi buffaloes. Further studies on Y-chromosome specific genes in a larger number of diversified groups of animals covering different geographical regions could aid to ascertain potential SNP markers associated with semen production.

Conflict of interest: None.

\section{REFERENCES}

Anonymous, (2019). Basic Animal Husbandry and Fisheries Statistics. Department of Animal Husbandry and Dairying, Ministry of Fisheries, Animal Husbandry and Dairying, Government of India. http://www.dahd.nic.in/Division/ statistics/animal-husbandry-statistics-division.

Bhakat, M., Mohanty, T.K., Gupta, A.K., Prasad, S., Chakravarty, A.K., Khan, H.M. (2015). Effect of season on semen quality parameters in Murrah buffalo bulls. Buffalo Bulletin. 34(1): 100-112.

Gopinathan, A. (2014). Genetic studies on semen production in Jersey crossbred and Holstein Friesian crossbred bulls. Ph.D. Thesis submitted to the Tamil Nadu Veterinary and Animal Sciences University, Chennai, India.

Hussain, T., Manzoor, M.M., Wajid, A., Nadeem, A., Ali, A., Ali Shah, S., Abbas, K., Nawaz, A., De Donato, M., Ellahi Babar, M. (2013). High conservation of SRY gene in Buffalo compared to other Bovids. Buffalo Bulletin. 32(2): 666-670.

Jayakumar, S. (2006). Molecular characterization of SRY gene in Murrah buffaloes. M.V.Sc. Thesis submitted to the National Dairy Research Institute, Deemed University, Karnal, India.

Kaur, A., Mukhopadyay, C.S., Arora, J.S., Brah, G.S., Kaur, S., Jamir, C.J. (2014). Detection of single nucleotide polymorphism of holandric genes and association with sperm nuclear maturity in bovines. Indian Journal of Dairy Science. 67(6): 498-503.

Kaustubh, B., Thilak Pon Jawahar, K., Venkataramanan, R., Shivaji, S., Gautami, J., Vincent, D. (2020). Semen production and semen quality of indigenous buffalo breeds under hot semiarid climatic conditions in India. Tropical Animal Health and Production. 52: 2529-2539.

Kumar, A.S. and Krupakaran, R.P. (2014). Comparative study on physico-morphological characteristics of semen from Murrah buffaloes and Jersey crossbred cattle. CIB Tech Journal of Bio-Protocols. 3(3): 12-14. 
Mukherjee, A., Dass, G., Jagan Mohanarao, G., Gohain, M., Brahma, B., Tirtha Kumar, D., Sachinandan, D. (2013). Absolute copy number differences of $Y$ chromosomal genes between crossbred (Bos taurus $X$ Bos indicus) and Indicine bulls. Journal of Animal Science and Biotechnology. 4(1): 15.

Mukhopadhyay, C.S., Gupta, A.K., Yadav, B.R., Mohanty, T.K. (2011). Exploration of Y-chromosome specific markers to discover SNP associated with sub fertility traits in dairy bulls. Indian Journal of Biotechnology. 10(2): 178-182.

Ravimurugan, T. (2001). Semen production capacity of Murrah buffalo bulls in Tamil Nadu. M.V.Sc. Thesis submitted to the Tamil Nadu Veterinary and Animal Sciences University, Chennai, India.
Sambrook, J., Fritsch, E.F., Maniatis, T. (1989). Molecular Cloning: A Laboratory Manual (2nd Edn.). Cold Spring Harbor, New York. ISBN-10:9780879693091.

Singh, A.P., Singh, R., Singh, A.K., Gupta, A.K., Raina, V.S. (2013). Influence of microclimate modification on sexual behavior and semen characteristics of Murrah buffalo bull during hot humid period in India. Indian Journal of Animal Sciences. 83(4): 431-434.

Snedecor, G.W. and Cochran, W.G. (1989). Statistical Methods. lowa State University Press, USA. 